\title{
Treating atopic dermatitis: safety, efficacy, and patient acceptability of a ceramide hyaluronic acid emollient foam
}

This article was published in the following Dove Press journal:

Clinical, Cosmetic and Investigational Dermatology

5 May 2012

Number of times this article has been viewed

\author{
Omar Pacha \\ Adelaide A Hebert \\ Department of Dermatology, \\ University of Texas Health Science \\ Center, Houston, TX, USA
}

Correspondence: Omar Pacha

Department of Dermatology, University of Texas Health Science Center, 6655 Travis Street, Suite 600,

Houston, TX 77030, USA

Tel +17135008276

Fax +I 7I35243432

Email omar.pacha@uth.tmc.edu
Abstract: Advances in current understanding of the pathophysiology of atopic dermatitis have led to improved targeting of the structural deficiencies in atopic skin. Ceramide deficiency appears to be one of the major alterations in atopic dermatitis and the replenishment of this epidermal component through topically applied ceramide based emollients appears to be safe, well tolerated, and effective. Recently a ceramide hyaluronic acid foam has become commercially available and increasing evidence supports its safety and efficacy in patients who suffer from atopic dermatitis.

Keywords: atopic dermatitis, ceramide, Hylatopic, eczema, non-steroidal, dermatology

\section{Current understanding}

Atopic dermatitis (AD) is one of the most common dermatologic disorders known, occurring in up to 20 percent of Caucasian school children. ${ }^{1,2}$ Due to this high prevalence in the pediatric population, a tremendous amount of effort has been expended to elucidate the pathophysiology and etiology of this skin condition. Current understanding of this cutaneous disorder including the genetics, immunology, response to microbes, and the breakdown of the skin as a barrier have facilitated the development of products that remedy the deficits now recognized in the outermost layers of the skin. The breakdown of the skin barrier recognized in AD is due to impairment of the stratum corneum resulting from a diminution in lipids, chiefly ceramides. ${ }^{3}$ The stratum corneum lipids serve to retain water as well as providing a permeability barrier. This barrier is made up of several components including the corneocytes and their surrounding mature lamellar bodies filled with ceramides, cholesterol, and fatty acids. These hydrophobic molecules provide the skin with a means to circumvent the loss of moisture which would result in the breakdown of the epidermal protective layer, superinfection by opportunistic organisms, and an increase in antigen exposure. Current treatment norms consist of both restoration of the barrier using traditional emollients and altering the immune hyper-responsiveness with topical steroids or immunomodulators. ${ }^{4}$ Traditional emollients or moisturizers include ointments, emulsions, and creams that work by reducing transepidermal water loss either through occlusion or the attraction of moisture through humectants. These alone or in combination have proven to be safe and effective when used correctly. Most patients with mild to moderate AD will respond to a regimen of enhanced lubrication, especially if pruritus and bacterial colonization are also managed effectively. ${ }^{5}$ The well-known potential side effects of topical steroids including systemic absorption, thinning of the skin, telangiectasia, 
striae, rosacea, and acne, ${ }^{6}$ while infrequently encountered, are often unacceptable to patients and parents. Further certain traditional emollients in lotion or ointment bases are often in formulations that patients will rarely use consistently.

\section{Common emollient ingredients in HylatopicPlus ${ }^{\circledR}$}

Dimethicone is a polymer of silicone and oxygen that works as an effective occlusive. Dimethicone's popularity and widespread use is likely attributable to its property of "oil free" occlusion and the ascribed safety and tolerability of this component. ${ }^{7}$ Furthermore in addition to the dimethicone added as an occlusive, HylatopicPlus ${ }^{\circledR}$ (Onset Dermatologics, Cumberland, RI) also includes petrolatum.

Glycerin is a simple organic compound that functions as a humectant. Like all humectants, without appropriate occlusion this can actually increase transepidermal water loss by attracting additional moisture from the dermis into the epidermis with ultimate loss of cutaneous moisture into the ambient air. ${ }^{8}$

Propylene glycol is a simple organic compound that also functions as a humectant. Historically this ingredient was believed to be a common cause of contact dermatitis. More recently, this has been recognized not to be the case in most available dermatologic products. In concentrations above 5\% propylene glycol may cause an irritant contact dermatitis although this immune-mediated response is unlikely at the lower concentrations used in most newer emollients such as HylatopicPlus. Furthermore, true allergic contact dermatitis from propylene glycol is rare for most available over-the-counter emollients. ${ }^{9}$

\section{Compliance based on properties of various prior emollient studies}

Patient compliance in chronic dermatologic conditions is quite poor. Recognition of this phenomenon has led to speculation that improvement in vehicle properties which would cater to patient preferences could potentially improve therapeutic adherence. Noncompliance rates may be as high as $40 \%$ in chronic dermatologic conditions. ${ }^{10}$ Patients appear to prefer topical foams and solutions to ointments and oils regardless of ethnic background or site of application. This preference for foams and solutions also appears to improve compliance ${ }^{11}$ and suggests that a focus on vehicles that cater to patient preferences would improve compliance and ultimately their underlying cutaneous condition.

\section{Function of emollients in the epidermal barrier: how do these agents repair the skin biochemically?}

Emollients work in the treatment of AD by improving the barrier function of the skin. The "outside in" theory of $\mathrm{AD}$ contends that certain genetic abnormalities lead to a defective skin barrier that allows allergens and pathogens to penetrate. The resultant increased water loss and an allergic inflammatory response with release of cytokines can exacerbate skin damage. Patients who have mutations in the gene that encodes for filaggrin have a threefold increased risk of AD. ${ }^{12}$ Filaggrin, an interfilamentous protein that aggregate keratin into tight bundles, induces the corneocyte to become flattened. ${ }^{13}$ Individuals who have the filaggrin mutations have different ratios of ceramide types and generally lower quantities of certain ceramides than nonatopic patients. ${ }^{14}$ While traditional emollients improve xerosis and may reduce antigen exposure, ceramide-dominant emollients appear to improve barrier function and break the cycle of antigen exposure, inflammation, and water loss. Transepidermal water loss and desquamation are increased in AD. Consistent use of emollients reduces the level of both of these phenomena. However, use of traditional emollients does not have any effect on inflammatory cytokine levels or ceramide levels. ${ }^{15}$ These traditional non-ceramide-based emollients alleviate symptoms but do not address the fundamental element of the problem, that is, a ceramide deficiency. Application of ceramide-containing emollients changes the structure of the stratum corneum to replenish and restore the number and structure of extracellular lipid bilayer components as compared to untreated atopic skin. ${ }^{16}$ Objective measurements, like the severity scoring of AD, SCORAD, ${ }^{17}$ and transepidermal water loss have both demonstrated greater improvement after application of ceramide emollients over traditional emollients. ${ }^{18}$

Topical calcineurin inhibitors have become an alternative to topical steroids in the treatment of AD. These have a relatively benign side effect profile and can be used on the face and intertriginous areas. Calcineurin inhibitors work by blocking T-cell activation and replication, ultimately dulling TNF alpha levels. When comparing 1\% pimecrolimus cream to foam ceramide-containing emollients in an investigator blinded head-to-head comparison trial, both products resulted in a substantial improvement in patient symptoms and the investigator's global assessment. There was no statistically significant difference in the efficacy of topical ceramide foam 
when compared to pimecrolimus cream. ${ }^{6}$ The basis for the action of the hyaluronic-containing emollient is the delivery of the moisturizer through the stratum corneum and into the dermis, thereby theoretically depositing ceramide proteins in the most anatomically valuable location. ${ }^{19}$ Hyaluronic acid also interacts with CD44 on the surface of keratinocytes, stimulating lamellar body formation and secretion. ${ }^{20}$

\section{What evidence is there of the safety of ceramide emollients?}

Compared to the even small risks of topical steroids or immunomodulators, topical ceramides appear to be quite safe. Topical steroids may potentially cause cutaneous atrophy, striae, telangiectasias, and acne. Systemic absorption is always a potential concern. Topical calcineurin inhibitors like pimecrolimus (Elidel ${ }^{\circledR}$, Novartis, Basel, Switzerland) cream or tacrolimus (Protopic ${ }^{\circledR}$, Astellas Pharma Inc, Tokyo, Japan) ointment have received black box warnings as a class of topical immunomodulators based on the theoretical risk of increasing malignancy. ${ }^{21}$ This black box warning is the only one ever given by the FDA based on a theoretical risk that currently appears to be poorly substantiated. These warnings have not led to commensurate label changes outside the United States. ${ }^{22-25}$ Topical application of these calcineurin inhibitors generally appears to be safe. There is no need for laboratory monitoring when topical calcineurin inhibitors are prescribed, as compared to systemic treatment of $\mathrm{AD}$ with methotrexate or cyclosporine which potentially can lead to serious side effect profiles including teratogenicity and leukopenia. By comparison, review of the profile of ceramide-containing emollients recently has shown these agents to be extremely safe. ${ }^{26}$

Nine ceramides are present in the stratum corneum. ${ }^{6}$ These important compounds comprise half of the lipids in the stratum corneum which help to mediate the permeability of the stratum corneum barrier. As these polar lipids are present in large quantities in normal skin, many current topical regimens also contain ceramides in large quantities.

Ceramides are available in two ways: via synthetic synthesis (which normally provides an economical and pure source of ceramides); or from natural sources which, while more biologically similar to those found in human skin, are often more expensive. The natural-source ceramides have a risk of contamination and may be viewed as potential sources of infection. Natural sources of ceramides include bovine central nervous systems, raising concern about contamination with prions that can transmit bovine spongiform encephalopathy or "mad cow disease." 27 Further, ceramide can be involved in cellular signaling and, in sufficient quantities, can be toxic to cells by migrating across the cell membrane and inducing apoptosis or inhibiting growth. ${ }^{28}$ Cell-permeant ceramide inhibits keratinocyte proliferation and increases cytotoxicity by disrupting the mitochondrial membrane action potential. Thus, natural ceramides, while intuitively the better option, are not perfect agents for topical emollients. Synthetic ceramides can be pure, cheaper to produce, and have characteristics that produce effects that are desirable without the unwanted potential biologic effects, because these lipids do not penetrate the cell membrane. ${ }^{29}$ Synthetic ceramides even at $100 \%$ presumed absorption after application have not been found to produce any ill effects either on skin, test animal eyes, or with oral administration. ${ }^{26}$

\section{What evidence is there of acceptability to patients?}

Previously, patients requiring long-term use of topical corticosteroid had no alternative therapies readily available to them. Now, however, topical calcineurin inhibitors offer a nonsteroidal alternative with the advantage of avoiding common topical steroid-induced side effects. The calcineurin inhibitors may be difficult to prescribe for particularly anxious patients who have been scared by their "internet research," piquing their concern for potential increased malignancy or who simply want the "safest" alternative. Furthermore calcineurin inhibitors are FDA approved for the treatment of children 2 years of age and older. Topical ceramide emollient foams offer cutaneous barrier improvement, are remarkably safe, and are approved for use even in young children.

\section{Costs and conclusion}

As cost may impact compliance and indirectly, efficacy, newer prescription devices like Hylatopic, which are expensive, must be evaluated with respect to cost versus benefit. The use of traditional emollients and topical steroids is effective in the majority of patients suffering from $\mathrm{AD}$ and these agents can be employed safely and inexpensively. The addition of topical calcineurin inhibitors is a safe and effective therapy or these agents may serve as augmentation to treatment. Further understanding of the pathophysiology of $\mathrm{AD}$ has resulted in new, effective, and safe treatment in those patients who have failed other regimens or refuse to use those modalities to effectively control the underlying skin disease. 


\section{Disclosure}

Omar Pacha has no conflicts of interest to disclose in relation to this work. Adelaide A Hebert has been a speaker for Onset Dermatologics regarding HylatopicPlus - Aurstat Kit.

\section{References}

1. Schultz-Larsen F, Hanifin JM. Epidemiology of atopic dermatitis. Immunol Allergy Clin North Am. 2002;22(1):1-24.

2. Marks R, Kilkenny M, Plunkett A, Merlin K. The prevalence of common skin conditions in Australian school students: 2. Atopic dermatitis. $\mathrm{Br}$ J Dermatol. 1999;140(3):468-473.

3. Imokawa G, Abe A, Jin K, Higaki Y, Kawashima M, Hidano A. Decreased level of ceramides in stratum corneum of atopic dermatitis: an etiologic factor in atopic dry skin? J Invest Dermatol. 1991;96(4): 523-526.

4. Paller A, Eichenfield LF, Leung DY, Stewart D, Appell M. A 12-week study of tacrolimus ointment for the treatment of atopic dermatitis in pediatric patients. J Am Acad Dermatol. 2001;44(Suppl 1):S47-S57.

5. Callen J, Chamlin S, Eichenfield LF, et al. A systematic review of the safety of topical therapies for atopic dermatitis. Br J Dermatol. 2007; 156(2):203-221.

6. Frankel A, Sohn A, Patel RV, Lebwohl M. Bilateral comparison study of pimecrolimus cream $1 \%$ and a ceramide-hyaluronic acid emollient foam in the treatment of patients with atopic dermatitis. J Drugs Dermatol. 2011;10(6):666-672.

7. Draelos ZD. Therapeutic moisturizers. Dermatol Clin. 2000;18(4): 597-607.

8. Lodén M, Wessman W. The influence of a cream containing $20 \%$ glycerin and its vehicle on skin barrier properties. Int J Cosmet Sci. 2001;23(2):115-119.

9. Lessmann H, Schnuch A, Geier J, Uter W. Skin-sensitizing and irritant properties of propylene glycol. Contact Dermatitis. 2005; 53(5):247-259.

10. Richards HL, Fortune DG, O’Sullivan TM, Main CJ, Griffiths CE. Patients with psoriasis and their compliance with medication. $J \mathrm{Am}$ Acad Dermatol. 1999;41(4):581-583.

11. Feldman SR, Housman TS. Patients' vehicle preference for corticosteroid treatments of scalp psoriasis. Am J Clin Dermatol. 2003; 4(4):221-224

12. Weidinger S, O'Sullivan M, Illig T, et al. Filaggrin mutations, atopic eczema, hay fever, and asthma in children. J Allergy Clin Immunol. 2008;121(5):1203-1209.

13. Candi E, Schmidt R, Melino G. The cornified envelope: a model of cell death in the skin. Nat Rev Mol Cell Biol. 2005;6(4):328-340.

14. Jungersted JM, Scheer H, Mempel M, et al. Stratum corneum lipids, skin barrier function and filaggrin mutations in patients with atopic eczema. Allergy. 2010;65(7):911-918.

15. Kikuchi K, Tagami H; Japanese Cosmetic Scientist Task Force for Skin Care of Atopic Dermatitis. Noninvasive biophysical assessments of the efficacy of a moisturizing cosmetic cream base for patients with atopic dermatitis during different seasons. Br J Dermatol. 2008;158(5): 969-978.
16. Chamlin SL, Kao J, Frieden IJ, et al. Ceramide-dominant barrier repair lipids alleviate childhood atopic dermatitis: changes in barrier function provide a sensitive indicator of disease activity. $J$ Am Acad Dermatol. 2002;47(2):198-208.

17. Kunz B, Oranje AP, Labreze L, Stalder JF, Ring J, Taieb A. Clinical validation and guidelines for the SCORAD index: consensus report of the European Task Force on Atopic Dermatitis. Dermatology. 1997; 195:10-19.

18. Lee EJ, Lee JH, Jin CY, Park BD. Original Articles: The Clinical Efficacy of a Multi-Lamellar Emulsion Containing Pseudoceramide in Childhood Atopic Dermatitis: An Open Crossover Study. Annals of Dermatology. 2003;15:133-138.

19. Spencer TS. Dry skin and skin moisturizers. Clin Dermatol. 1988;6(3): 24-28.

20. Bourguignon LY, Ramez M, Gilad E, et al. Hyaluronan-CD44 interaction stimulates keratinocyte differentiation, lamellar body formation/ secretion, and permeability barrier homeostasis. J Invest Dermatol. 2006;126(6):1356-1365.

21. Jain AB, Yee LD, Nalesnik MA, et al. Comparative incidence of de novo nonlymphoid malignancies after liver transplantation under tacrolimus using surveillance epidemiologic end result data. Transplantation. 1998; 66(9):1193-1200.

22. Ormerod AD. Topical tacrolimus and pimecrolimus and the risk of cancer: how much cause for concern? Br J Dermatol. 2005;153(4): 701-705.

23. Ring J, Möhrenschlager M, Henkel V. The US FDA 'Black Box' warning for topical calcineurin inhibitors: an ongoing controversy. Drug Saf. 2008;31(3):185-198.

24. Hultsch T, Kapp A, Spergel J. Immunomodulation and safety of topical calcineurin inhibitors for the treatment of atopic dermatitis. Dermatology. 2005;211(2):174-187.

25. Fleischer AB. Black box warning for topical calcineurin inhibitors and the death of common sense. Dermatol Online J. 2006;12(6):2.

26. Uchida Y, Holleran WM, Elias PM. On the effects of topical synthetic pseudoceramides: Comparison of possible keratinocyte toxicities provoked by the pseudoceramides, PC104 and BIO391, and natural ceramides. J Dermatol Sci. 2008;51(1):37-43.

27. Adkin A, Webster V, Arnold ME, Wells GAH, Matthews D. Estimating the impact on the food chain of changing bovine spongiform encephalopathy (BSE) control measures: The BSE Control Model. Preventive Veterinary Medicine. 2010;93(2-3):170-182.

28. Ganapathi SB, Fox TE, Kester M, Elmslie KS. Ceramide modulates HERG potassium channel gating by translocation into lipid rafts. $\mathrm{Am}$ J Physiol Cell Physiol. 2010;299(1):C74-C86.

29. Garcia-Ruiz C, Colell A, Mari M, Morales A, Fernández-Checa JC. Direct effect of ceramide on the mitochondrial electron transport chain leads to generation of reactive oxygen species. J Biol Chem. 1997; 272(17):11369-11377.
Clinical, Cosmetic and Investigational Dermatology

\section{Publish your work in this journal}

Clinical, Cosmetic and Investigational Dermatology is an international, peer-reviewed, open access, online journal that focuses on the latest clinical and experimental research in all aspects of skin disease and cosmetic interventions. All areas of dermatology will be covered; contributions will be welcomed from all clinicians and

\section{Dovepress}

basic science researchers globally. This journal is indexed on CAS The manuscript management system is completely online and includes a very quick and fair peer-review system, which is all easy to use. Visit http://www.dovepress.com/testimonials.php to read real quotes from published authors. 